\title{
ПЕРСИСТИРОВАНИЕ ОНКОЛИТИЧЕСКОГО ЭНТЕРОВИРУСА КОКСАКИ А7 В ПОДКОЖНЫХ МЫШИНЫХ КСЕНОТРАНСПЛАНТАТАХ ГЛИОБЛАСТОМ ЧЕЛОВЕКА ПРИ ЭКСПЕРИМЕНТАЛЬНОЙ ТЕРАПИИ
}

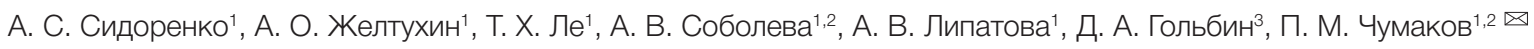 \\ Институт молекулярной биологии имени В. А. Энгельгардта, Москва \\ Федеральный научный центр исследований и разработки иммунобиологических препаратов имени М. П. Чумакова, Москва \\ з Национальный медицинский исследовательский центр нейрохирургии имени Н. Н. Бурденко, Москва
}

\begin{abstract}
Природные непатогенные и вакцинные штаммы энтеровирусов человека в настоящее время рассмариваются в качестве перспективных средств для лечения онкологических заболеваний, в том числе мультиформной глиобластомы наиболее агрессивной опухоли головного мозга, для которой не существует эффективных средств терапии. Энтеровирусы могут избирательно реплицироваться в клетках опухоли, вызывая их лизис. Однако способность энтеровирусов длительно присутствовать в опухолевой ткани и совершать несколько последовательных циклов репликации с распространением от клетки к клетке плохо изучена. Целью исследования было установление возможности полного уничтожения подкожных ксенотрансплантатов глиобластом человека при однократном введении вируса внутривенной доставкой с помощью лейкоцитов периферической крови, а также длительность присутствия (персистирования) вируса в организме экспериментальных животных в процессе вирусной терапии. В качестве опухолевых клеток использовали нейросферы, полученные in vitro путем инкубации фрагментов удаленных у пациентов опухолей. Установлено, что лейкоциты периферическойкрови человека, инфицированные in vitro, способны осуществлять эффективную доставку в клетки опухоли вируса Коксаки А7. Однократное введение $2 \times 10^{4}$ зараженных вирусом лейкоцитов приводило к постепенной регрессии опухолей при постоянно определяющемся присутствии вируса в крови мыши. По результатам исследования сделан вывод, что доставка энтеровируса Коксаки А7 в опухоль может быть эффективно осуществлена с помощью лейкоцитов крови. В отсутствие полноценного иммунного ответа в опухолях у мышей наблюдается персистирование вирусов, заканчивающееся их полным уничтожением.
\end{abstract}

Ключевые слова: мультиформная глиобластома, вирус Коксаки А7, вирусный онколиз, мышиные модели, ксенотрансплантаты опухолей, экспериментальная терапия, онколитические вирусы

Финансирование: работа выполнена при финансовой поддержке Министерства образования и науки РФ, уникальный код проекта RFMEFI60714X0014.

$\bowtie$ Для корреспонденции: Петр Михайлович Чумаков

ул. Вавилова, д. 32, г. Москва, 119991; chumakovpm@yahoo.com

Статья получена: 13.07.2018 Статья принята к печати: 16.07 .2018

DOI: $10.24075 /$ vrgmu.2018.032

\section{PERSISTENCE OF ONCOLYTIC COXSACKIE VIRUS A7 IN SUBCUTANEOUS HUMAN GLIOBLASTOMA XENOGRAFTS IN MICE IN THE CONTEXT OF EXPERIMENTAL THERAPY}

\author{
Sidorenko $A S^{1}$, Zheltukhin $\mathrm{AO}^{1}$, Le $\mathrm{TH}^{1}$, Soboleva $\mathrm{AV}^{1,2}$, Lipatova $\mathrm{AV}^{1}$, Golbin $\mathrm{DA}^{3}$, Chumakov $\mathrm{PM}^{1,2} \otimes$ \\ Engelhardt Institute of Molecular Biology, Moscow \\ ${ }^{2}$ Chumakov Federal Scientific Center for Research and Development of Immune-and-Biological Products, Moscow \\ ${ }^{3}$ Burdenko National Medical Research Center of Neurosurgery, Moscow
}

Natural non-pathogenic and vaccine strains of human enteroviruses are currently considered as promising agents capable of treating various kinds of cancer, including glioblastoma multiforme, the most aggressive brain tumor with so far no effective therapy. Enteroviruses can selectively replicate in cancer cells and cause tumor lysis. However, the ability of enteroviruses to persist in tumor tissue for a long period of time and to replicate in several successive cycles while spreading from cell to cell remains largely unclear. This study aimed to determine the possibility of completely destroying subcutaneous mouse xenografts of human glioblastomas through a single intravenous administration of virus-carrying peripheral blood leukocytes, as well as to find out the duration of persistence of the virus in the body of experimental animals in the context of viral therapy. Neurospheres were formed in vitro by incubating fragments of patients-derived glioblastomas and used to initiate subcutaneous tumors in immunodeficient mice. It was established that human peripheral blood leukocytes infected in vitro can effectively deliver Coxsackie A7 virus to the tumor cells. A single injection of $2 \times 10^{4}$ virus-infected leukocytes led to a gradual regression of tumors, while the virus presence was constantly detectable in the blood of mice, up to the complete regression of the tumors. The study allows to make the conclusion that blood leukocytes can effectively deliver Coxsackie A7 virus to the tumor. In the absence of a full-fledged immune response in mice, the viruses persist in tumors leading to their complete destruction.

Keywords: glioblastoma multiforme, Coxsackie A7 virus, viral oncolysis, mice models, tumor xenografts, experimental therapy, oncolytic viruses

Funding: the study was supported by the Ministry of Education and Science of the Russian Federation; project code RFMEFI60714X0014.

$\triangle$ Correspondence should be addressed: Peter M. Chumakov

Vavilova 32, Moscow, 119991; chumakovpm@yahoo.com

Received: 13.07.2018 Accepted: 16.07.2018

DOI: 10.24075/brsmu.2018.032 
Терапия опухолей головного мозга, особенно мультиформной глиобластомы, по-прежнему остается нерешенной проблемой $[1,2]$. Особое значение приобретают поиски новых альтернативных подходов к лечению. Основная их проблема связана с устойчивостью стволовых клеток опухоли к существующим терапевтическим воздействиям, приводящей к неизбежным рецидивам заболевания. Многие онколитические вирусы способны эффективно уничтожать стволовые клетки глиобластом и предотвращать рецидивирование [3-8]. В ходе развития опухоли ее клетки приобретают ряд характерных свойств, которые могут быть использованы в качестве специфических мишеней для терапии [9]. Кроме того, они утрачивают многие функции, необходимые им для существования в многоклеточном организме [10-12] В числе этих функций - защита клеток от вирусов [1315]. Опухолевые клетки при заражении их вирусами, как правило, не способны индуцировать интерфероны 1 типа но приобретают невосприимчивость к реинсекции вирусами после обработки интерферонами [16-20]. Этим обусловлена повышенная чувствительность опухолевых клеток к заражению представителями многих семейств вирусов, что лежит в основе разработки терапевтических штаммов онколитических вирусов [21-24]. Механизм действия онколитических вирусов связан не только с избирательным заражением и уничтожением раковых клеток, но и со значительной активацией противоопухолевого иммунитета и модификацией опухолевого микроокружения. Под действием онколитических вирусов происходит стимулирование врожденного и адаптивного видов иммунитета, что сопровождается стойким противоопухолевым действием даже после окончания репликации вирусов в клетках опухоли [25-28] Представители онколитических вирусов разных семейств используют каждый из перечисленных механизмов в различной степени. Вклад прямого вирусного онколиза, вызванного непосредственным размножением вирусов в опухолевых клетках, удобно изучать на модели опухолевых ксенотрансплантатов у иммунодефицитных бестимусных мышей, у которых многие компоненты противоопухолевого иммунитета нарушены [29], или у мышей с тяжелым комбинированным иммунодесиицитом (SCID) [30]. Эти модели также удобны для отработки способов доставки вирусов в опухоль. Введение вируса должно приводить к эфффективному заражению части опухолевых клеток, которое инициирует последующие циклы репликации вируса с выходом из зараженной клетки и перезаражением новых опухолевых клеток, находящихся в данном или отдаленном опухолевом узле. Если введение вируса непосредственно в чувствительную к вирусу опухоль возможно прямой инъекцией, то этот процесс запускается без особых затруднений. Однако в большинстве случаев метастатических форм рака, а также опухолей с затрудненным доступом, такой подход неприменим. Системное введение вируса путем внутривенных или внутримышечных инъекций зачастую тоже малоэфффективно, поскольку вирус очень быстро выходит из циркуляции в результате поглощения клетками эндотелия и действия неспецифических защитных факторов крови. Перспективной альтернативой системной доставке является использование клеток-носителей - зараженных in vitro чувствительных к вирусу клеток, вводимых в кровоток [31-33]. Репликация вируса в таких клеткахпроисходит в процессе их системной циркуляции с последующим выходом инфекционных частиц в отдаленных участках организма, в том числе в опухоли. В данном исследовании мы использовали модель подкожных опухолевых ксенотрансплантатов глиобластом человека: иммунодефицитным мышам вводили клетки из нейросферных культур, полученных из опухолевого материала двух больных с глиобластомами. Нейроссреры - плотные скопления клеток, образующихся при культивировании опухолевых эксплантатов в условиях, препятствующих прикреплению к поверхности чашки, и специальной среде, в составе которой имеются эпидерамальный фактор роста и фактор рост фибробластов (EGF, bFGF соответственно) [34, 35]. Как и другие сфероиды, полученные из опухолей человека, нейросферы обогащены опухолевыми стволовыми клетками [36], поэтому обладают повышенной туморогенностью $[37,38]$. Целью работы было отработать процедуру доставки онколитических энтеровирусов с помощью лейкоцитов периферической крови, используя модель подкожных опухолевых ксенотрансплантатов у мышей, и установить продолжительность присутствия (персистирования) вируса в организме экспериментальных животных в процессе вирусной терапии.

\section{МАТЕРИАЛЫ И МЕТОДЬ}

\section{Культура клеток для титрования вирусов}

Культуру клеток Vero (иммортализованные клетки почки африканской зеленой обезьяны) выращивали в среде DMEM (ПанЭко, Россия) сдобавлением 10\% эмбриональной сыворотки теленка (FBS), 100 мг/мл пенициллина и 100 мг/мл стрептомицина. Клетки наращивали в 10-см пластиковых культуральных чашках во влажной атмосфере, содержащей 5\% $\mathrm{CO}_{2}$, при температуре $37^{\circ} \mathrm{C}$, затем рассевали каждые 3 суток в соотношении 1:4-1:6.

\section{Нейросферные опухолеобразующие культуры клеток глиобластомы}

Происхождение и получение культур клеток из материала пациентов с глиобластомой (GM-3564 и GM-3876) описаны ранее [39]. Для повышения опухолеобразования подкожное введение нейросфер производили иммунодефицитным мышам линии SCID/Beige, используя их в качестве экспериментальных животных (штамм мышей был получен из Новосибирского SPF вивария и поддержавается в лаборатории). Нейросферы глиобластом, прошедшие не более двух пассирований в культуре, хранили при температуре жидкого азота и размораживали непосредственно перед началом экспериментов. Их высевали на среду $\mathrm{DMEM}+\mathrm{F} 12$ (ПанЭко, Россия), содержащую 20 нг/мл EGF и 10 нг/мл bFGF, и помещали в инкубатор с 5\% CO при $37^{\circ} \mathrm{C}$. После формирования нейроссер (через 7-10 суток) их дважды отмывали физиологическим солевым раствором (PBS), подсчитывали, аккуратно пипетировали до исчезновения крупных агрегатов клеток и вводили подкожно мышам линии SCID/Beige из расчета 500 сфероидов на точку введения. Опухоли появились через 3 недели. Новообразования размером около 10 мм в диаметре иссекали, диспергировали продавливанием через стерильную нейлоновую сетку с диаметром пор 50 мкм, обрабатывали коллагеназой (ПанЭко, Москва) для получения суспензии клеток, отмывали дважды физиологическим раствором и полученную суспензию использовали для подкожного введения мышам SCID/Beige в количестве $2 \times 10^{5}$ клеток на точку введения с целью получения опухолей непосредственно для испытания онколитической активности вируса. Предварительная адаптация нейросфер к росту в виде опухолей на мышах 
приводила к увеличению туморогенности и повышению числа образовавшихся опухолей при повторном введении животным.

\section{Штамм онколитического вируса}

В исследовании использовали штамм ЖЭВ8 энтеровируса Коксаки A7 [40, 41], который обладает способностью эффективно реплицироваться в клетках GM-3564 и GM3876 [39]. Титрование инфекционной активности вирусных препаратов проводили методом конечных разведений на культуре клеток Vero с использованием 96-луночных планшетов.

\section{Доставка вируса с помощью лейкоцитов перефирической крови человека}

Фракцию лейкоцитов периферической крови получали из свежезабранной гепаринизированной крови человека с помощью центрифугирования в растворе Ficoll-Paque (ПанЭко, Россия) согласно стандартному протоколу [42]. Отмытые дважды средой DMEM лейкоциты подсчитывали и готовили суспензию с плотностью $10^{6}$ кл./мл. Суспензию инкубировали с вирусом Коксаки А7 (10 инфекционных единиц на клетку) при температуре $37^{\circ} \mathrm{C}$ в течение 14 . Затем лейкоциты отмывали 3 раза по 10 мл физиологическим солевым раствором (0,14 M NaCl), центрифугировали при 800 g 5 мин. Инфицированные лейкоциты в количестве $2 \times 10^{4}$ клеток вводили в объеме 0,1 мл в хвостовую вену мышам SCID/Beige, несущим опухоли объемом около 400-600 мкл. Наблюдение за размером опухолей проводили каждые трое суток. Для определения вируса в крови мышей каплю крови забирали из хвостовой вены и титровали на клетках Vero методом конечных серийных разведений в 96-луночных планшетах.

\section{РЕЗУЛЬТАТЫ ИССЛЕДОВАНИЯ}

Ранее нами было установлено, что культуры клеток GM3564 и GM-3876, полученные из опухолевого материала двух пациентов с глиобластомой, обладают высокой чувствительностью к вирусу Коксаки А7 [39]. В настоящем исследовании этот штамм вируса использовали для определения возможности его доставки в опухоль посредством клеточного носителя, а также для изучения его способности К длительному персистированию в опухоли, приводящему к стойкому онколитическому эфреекту. Для этого была использована модель подкожных ксенотрансплантатов нейросферных культур клеток GM3564 и GM-3876 на мышах линии SCID/Beige, имеющих комбинированную иммунную недостаточность. После подкожного введения нейросфер опухоли достигали объема 400-600 мкл за 10 суток. В эксперименте использовали две группы по 10 мышей для каждого типа опухолевых клеток (всего 4 группы): одной группе вводили в хвостовую вену инфицированные вирусом лейкоциты, другой - контрольные незараженные лейкоциты. На рис. 1 представлена динамика изменения размеров опухоли (в мм $\left.^{3}\right)$ при измерении каждые трое суток на протяжении 27 суток. В контрольной группе мышей при введении в хвостовую вену неинфицированных вирусом лейкоцитов рост опухолей продолжался и мышей, у которых он достигал размеров, приблизительно равных 1500 мм³, подвергали эвтаназии. Это происходило в интервале между 9 и 15 сутками после введения лейкоцитов. При введении в хвостовую вену инфицированных вирусами Коксаки A7 лейкоцитов увеличение объемов новообразований продолжалось еще в течение трех суток, после чего размер опухолей стремительно сокращался у мышей обеих групп, несущих клетки GM-3564 и GM-3876. Через 18-21 день после инъекций размеры опухолей уже невозможно

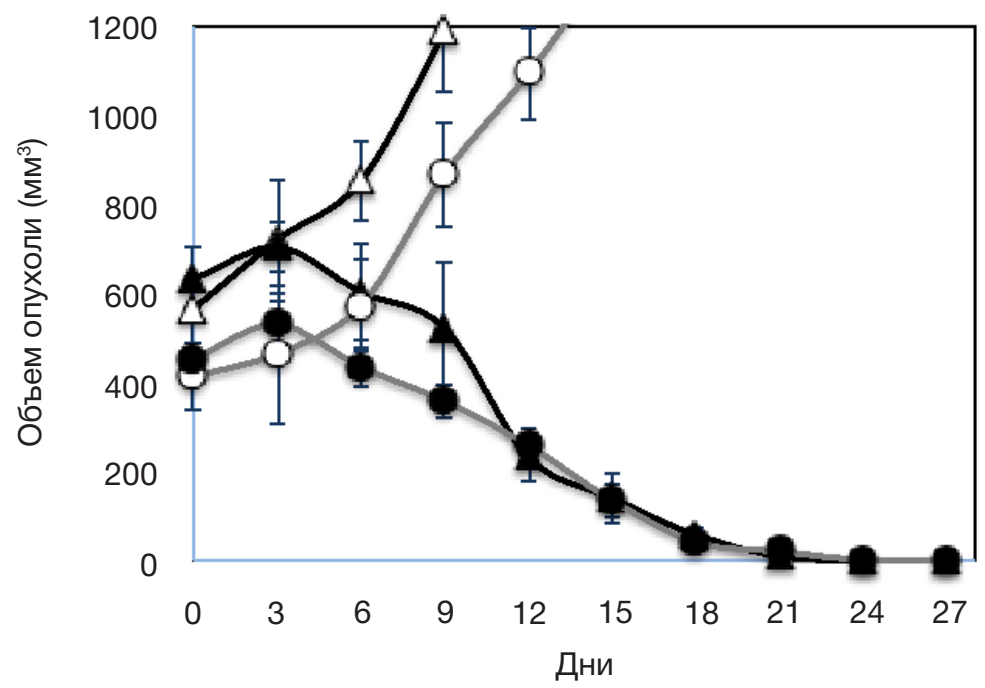

Рис. 1. Динамика изменений размеров подкожных опухолевых ксенотрансплантатов клеток глибластомы GM-3564 и GM-3876 неинфицированных лейкоцитов человека и лейкоцитов, инфицированных вирусом Коксаки А7. $\triangle$ - введение лейкоцитов мышам с опухолями GM-3564; $\boldsymbol{\Delta}$ - введение инфицированных лейкоцитов мышам с опухолями GM-3564; O - введение лейкоцитов мышам с опухолями GM-3876; - введение инфицированных лейкоцитов мышам с опухолями GM-3876

Таблица. Титры вируса Коксаки А7 в крови экспериментальных мышей, определенные в различные сроки после внутривенного введения инсицированных вирусом лейкоцитов

\begin{tabular}{|l|c|c|c|c|c|c|c|c|c|c|}
\hline Дни & 0 & 3 & 6 & 9 & 12 & 15 & 18 & 21 & 24 & 27 \\
\hline GM-3564 & н. & $1,5 \times 10^{2}$ & $1,7 \times 10^{4}$ & $3,2 \times 10^{3}$ & $2,6 \times 10^{3}$ & $6 \times 10^{2}$ & $1,9 \times 10^{2}$ & H. & H. & H. \\
\hline GM-3876 & H. & H. & $1,0 \times 10^{2}$ & $5,2 \times 10^{3}$ & $5 \times 10^{3}$ & $1,2 \times 10^{3}$ & $2,6 \times 10^{2}$ & H. & H. & H. \\
\hline
\end{tabular}

Примечание: н. — вирус не определяется. 
было установить и на их месте подкожно выявлялась лишь малозаметная рубцовая ткань. Одновременно в крови мышей каждые трое суток определяли титр вируса (табл.).

Вирус впервые обнаруживали в крови мышей через 3 суток после введения и его количество достигало пиковых значений на 6 сутки, после чего снижалось вместе с уменьшением размеров опухолей. Вирус переставал определяться через 18-21 день после введения инфицированных лейкоцитов, когда мыши уже были практически свободны от опухолей.

\section{ОБСУЖДЕНИЕ РЕЗУЛЬТАТОВ}

На модели ксенотрансплантатов глиобластомы человека, растущих на мышах с комбинированным иммунным десицитом линии SCID/Beige нами была установлена возможность доставки онколитического вируса Коксаки А7 в опухоль с помощью лейкоцитов периферической крови человека, инсицированных вирусом in vitro и введенных в хвостовую вену. Такой способ введения обеспечивал появление вируса в крови в среднем через трое суток и его присутствие там вплоть до исчезновения опухолей. Таким образом, персистенция вируса в организмах мышей была обусловлена присутствием в них чувствительных к вирусу опухолевых клеток, полное уничтожение которых приводило и к исчезновению вируса. Ранее мы уже наблюдали длительную персистенцию полиовируса 1 типа у мышей с ксенотрансплантатами глиобластомы линии А172, приводящую к одновременному исчезновению опухолей и вируса в крови мышей [43]. Однако в отличии от настоящего исследования в той работе мышам внутривенно вводили высокие дозы свободного вируса. Вирус Коксаки A7 проникает в клетки с помощью белка LIMP-II, кодируемого геном SCARB2 [44]. LIMP-II экспрессируется на поверхности многих типов клеток человека, в том числе лейкоцитов, и по-видимому, участвует в распространении вируса в организме и при энтеровирусных инфекциях, вызываемых некоторыми патогенными штаммами вирусов Коксаки А. Использованный нами способ доставки вируса в опухоль имеет ряд преимуществ перед системным введением свободных вирионов, поскольку находясь внутри клетки вирус защищен от действия антител и других факторов, ведущих к его инактивации. Мы допускаем, что внутри лейкоцитов крови вирус способен к ограниченной репликации, что обусловливает его появление в отдаленных участках организма, в том числе опухоли. Доставка с помощью лейкоцитов позволяет к тому же существенно снизить исходное количество вируса, необходимого для терапии. Дальнейшие испытания должны быть направлены на выяснение того, насколько этот способ введения пригоден для терапии онкологических больных.

\section{ВЫВОДЫ}

Установлено, что внутривенное введение онколитического штамма вируса Коксаки А7 иммунодефицитным мышам линии SCID/Beige с помощью инфицированных лейкоцитов приводит к быстрому уменьшению размеров и исчезновению подкожных ксенотрансплантатов опухолей, полученных их клеток глиобластом двух больных. При этом вирус активно размножался в организмах мышей в течение всего периода присутствия у них чувствительных опухолевых клеток. Результаты показывают, что даже в отсутствие Т-клеточного иммунитета у бестимусных мышей возможна полная деструкция глиобластомных опухолей благодаря прямому цитолитическому действию онколитического энтеровируса, а также указывает на эффективность введения вируса с помощью лейкоцитов в качестве клеточных векторов доставки.

\section{Литература}

1. Сосновцева А. О., Гриненко Н. Ф., Липатова А. В., Чумаков П. М., Чехонин В. П. Онколитические вирусы в терапии злокачественных глиом. Биомедицинская химия. 2016; 62 (4): 376-90.

2. Губанова Н. В., Гайтан А. С., Разумов И. А., Мордвинов В. А., Кривошапкин А. Л., Нетесов С. В. и др. Онколитические вирусы в терапии глиом. Молекулярная биология. 2012; 46(6): 726-38.

3. Wakimoto H, Kesari S, Farrell CJ, Curry WT, Jr, Zaupa C, Aghi M, et al. Human glioblastoma-derived cancer stem cells: establishment of invasive glioma models and treatment with oncolytic herpes simplex virus vectors. Cancer Res. 2009; 69 (8): 3472-81.

4. Alonso MM, Jiang H, Gomez-Manzano C, Fueyo J. Targeting brain tumor stem cells with oncolytic adenoviruses. Methods Mo Biol. 2012; 797: 111-25.

5. Cheema TA, Wakimoto H, Fecci PE, Ning J, Kuroda T, Jeyaretna DS, et al. Multifaceted oncolytic virus therapy for glioblastoma in an immunocompetent cancer stem cell model. Proc Natl Acad Sci USA. 2013; 110 (29): 12006-11. Epub 2013/06/12. DOl: 10.1073/pnas.1307935110. PubMed PMID: 23754388; PubMed Central PMCID: PMCPMC3718117.

6. van den Hengel SK, Balvers RK, Dautzenberg IJ, van den Wollenberg DJ, Kloezeman JJ, Lamfers ML, et al. Heterogeneous reovirus susceptibility in human glioblastoma stem-like cell cultures. Cancer Gene Ther. 2013; 20 (9): 507-13. Epub 2013/08/03. DOI: 10.1038/cgt.2013.47. PubMed PMID: 23907517.

7. Zhu Z, Gorman MJ, McKenzie LD, Chai JN, Hubert CG, Prager BC, et al. Zika virus has oncolytic activity against glioblastoma stem

cells. J Exp Med. 2017; 214 (10): 2843-57. Epub 2017/09/07. DOI: 10.1084/jem.20171093. PubMed PMID: 28874392; PubMed Central PMCID: PMCPMC5626408.

8. Csatary LK, Bakacs T. Use of Newcastle disease virus vaccine $(\mathrm{MTH}-68 / \mathrm{H})$ in a patient with high-grade glioblastoma. JAMA. 1999; 281 (17): 588-9.

9. Hanahan D, Weinberg RA. Hallmarks of cancer: the next generation. Cell. 2011; 144 (5): 646-74.

10. Желтухин А. О., Чумаков П. М. Повседневные и индуцируемые функции гена р53. Успехи биологической химии. 2010; 50: $447-516$.

11. Чумаков П. М. Функция гена р53: выбор между жизнью и смертью. Биохимия. 2000; 65 (1): 28-40. PubMed PMID: 10702638.

12. Чумаков П. М. Белок р53 и его универсальные функции в многоклеточном организме. Биохимия. 2007; 72 (13): 1399-421. PubMed PMID: 18282133; PubMed Central PMCID: PMC2709848.

13. Ivashkiv LB, Donlin LT. Regulation of type I interferon responses. Nat Rev Immunol. 2014; 14 (1): 36-49. Epub 2013/12/24. DOl: 10.1038/nri3581. PubMed PMID: 24362405; PubMed Central PMCID: PMCPMC4084561.

14. Stark GR, Darnell JE, Jr. The JAK-STAT pathway at twenty Immunity. 2012; 36 (4): 503-14. Epub 2012/04/24. DOl: 10.1016/.immuni.2012.03.013. PubMed PMID: 22520844; PubMed Central PMCID: PMCPMC3909993.

15. Zitvogel L, Galluzzi L, Kepp O, Smyth MJ, Kroemer G. Type I 
interferons in anticancer immunity. Nat Rev Immunol. 2015; 15 (7): 405-14. Epub 2015/06/02. DOI: 10.1038/nri3845. PubMed PMID: 26027717

16. Groner B, von Manstein V. Jak Stat signaling and cancer: Opportunities, benefits and side effects of targeted inhibition. Mol Cell Endocrinol. 2017; 451: 1-14. Epub 2017/06/04. DOl: 10.1016/j.mce.2017.05.033. PubMed PMID: 28576744.

17. Heiber JF, Barber GN. Evaluation of innate immune signaling pathways in transformed cells. Methods Mol Biol. 2012; 797: 217-38

18. Li Q, Tainsky MA. Epigenetic silencing of IRF7 and/or IRF5 in lung cancer cells leads to increased sensitivity to oncolytic viruses. PLoS One. 2011; 6 (12): e28683. Epub 2011/12/24. DOI: 10.1371/journal.pone.0028683. PubMed PMID: 22194884; PubMed Central PMCID: PMCPMC3237484.

19. Pikor LA, Bell JC, Diallo J-S. Oncolytic viruses: exploiting cancer's deal with the Devil. Trends in Cancer. 2015; 1 (4): 266-77.

20. Stojdl DF, Lichty B, Knowles S, Marius R, Atkins H, Sonenberg N, et al. Exploiting tumor-specific defects in the interferon pathway with a previously unknown oncolytic virus. Nat Med. 2000; 6 (7): 821-5.

21. Bell JC, McFadden G. Editorial overview: Oncolytic virusesreplicating virus therapeutics for the treatment of cancer. Curr Opin Virol. 2015; 13: viii-ix. Epub 2015/08/12. DOI: 10.1016/j. coviro.2015.07.005. PubMed PMID: 26260227.

22. Fukuhara $\mathrm{H}$, Ino $\mathrm{Y}$, Todo T. Oncolytic virus therapy: A new era of cancer treatment at dawn. Cancer Sci. 2016; 107 (10): 1373-9. Epub 2016/10/30. DOI: 10.1111/cas.13027. PubMed PMID: 27486853; PubMed Central PMCID: PMCPMC5084676.

23. Naik S, Russell SJ. Engineering oncolytic viruses to exploit tumor specific defects in innate immune signaling pathways. Expert Opin Biol Ther. 2009; 9 (9): 1163-76.

24. Russell SJ, Peng KW, Bell JC. Oncolytic virotherapy. Nat Biotechnol. 2012; 30 (7): 658-70.

25. Keller BA, Bell JC. Oncolytic viruses-immunotherapeutics on the rise. J Mol Med (Berl). 2016; 94 (9): 979-91. Epub 2016/08/06. DOI: 10.1007/s00109-016-1453-9. PubMed PMID: 27492706.

26. Miao D, Van Allen EM. Genomic determinants of cancer immunotherapy. Curr Opin Immunol. 2016; 41: 32-8. Epub 2016/06/03. DOI: 10.1016/j.coi.2016.05.010. PubMed PMID: 27254251.

27. Papaioannou NE, Beniata OV, Vitsos P, Tsitsilonis O, Samara P. Harnessing the immune system to improve cancer therapy. Annals of translational medicine. 2016; 4 (14): 261. Epub 2016/08/27. DOI: 10.21037/atm.2016.04.01. PubMed PMID: 27563648; PubMed Central PMCID: PMCPMC4971375.

28. Shen W, Patnaik MM, Ruiz A, Russell SJ, Peng KW Immunovirotherapy with vesicular stomatitis virus and PD-L1 blockade enhances therapeutic outcome in murine acute myeloid leukemia. Blood. 2016; 127 (11): 1449-58. Epub 2015/12/30. DOI: 10.1182/blood-2015-06-652503. PubMed PMID: 26712908; PubMed Central PMCID: PMCPMC4797021.

29. Liston A, Farr AG, Chen Z, Benoist C, Mathis D, Manley NR, et al. Lack of Foxp3 function and expression in the thymic epithelium. J Exp Med. 2007; 204 (3): 475-80. Epub 2007/03/14. DOI: 10.1084/jem.20062465. PubMed PMID: 17353370; PubMed Central PMCID: PMCPMC2137899.

30. Parney IF, Petruk KC, Zhang C, Farr-Jones M, Sykes DB, Chang LJ. Granulocyte-macrophage colony-stimulating factor and B7-2 combination immunogene therapy in an allogeneic Hu-PBL-SCID/ beige mouse-human glioblastoma multiforme model. Hum Gene Ther. 1997; 8 (9): 1073-85. Epub 1997/06/10. DOI: 10.1089/ hum.1997.8.9-1073. PubMed PMID: 9189765.
31. Willmon C, Harrington K, Kottke T, Prestwich R, Melcher A, Vile R. Cell carriers for oncolytic viruses: Fed Ex for cancer therapy. Mol Ther. 2009; 17 (10): 1667-76.

32. Collet G, Grillon C, Nadim M, Kieda C. Trojan horse at cellular level for tumor gene therapies. Gene. 2013; 525 (2): 208-16. Epub 2013/04/02. DOI: 10.1016/.gene.2013.03.057. PubMed PMID: 23542073.

33. Pan PY, Chen HM, Chen SH. Myeloid-derived suppressor cells as a Trojan horse: A cellular vehicle for the delivery of oncolytic viruses. Oncoimmunology. 2013; 2 (8): e25083. Epub 2013/10/02. DOI: 10.4161/onci.25083. PubMed PMID: 24083075; PubMed Central PMCID: PMCPMC3782526.

34. Kim SS, Pirollo KF, Chang EH. Isolation and Culturing of Glioma Cancer Stem Cells. Current protocols in cell biology. 2015; 67: 23.10.1-10. Epub 2015/06/11. DOI: 10.1002/0471143030. cb2310s67. PubMed PMID: 26061242; PubMed Central PMCID: PMCPmc4471477.

35. Lathia JD, Mack SC, Mulkearns-Hubert EE, Valentim CL, Rich JN. Cancer stem cells in glioblastoma. Genes Dev. 2015; 29 (12): 1203-17. Epub 2015/06/26. DOI: 10.1101/gad.261982.115. PubMed PMID: 26109046; PubMed Central PMCID: PMCPMC4495393.

36. Shaheen S, Ahmed M, Lorenzi F, Nateri AS. Spheroid-Formation (Colonosphere) Assay for in Vitro Assessment and Expansion of Stem Cells in Colon Cancer. Stem Cell Rev. 2016; 12 (4): 492-9. Epub 2016/05/22. DOI: 10.1007/s12015-016-9664-6. PubMed PMID: 27207017.

37. Dashzeveg NK, Taftaf R, Ramos EK, Torre-Healy L, Chumakova A, Silver DJ, et al. New Advances and Challenges of Targeting Cancer Stem Cells. Cancer Res. 2017; 77 (19): 5222-7. Epub 2017/09/21. DOI: 10.1158/0008-5472.can-17-0054. PubMed PMID: 28928129

38. Natsume A, Kato T, Kinjo S, Enomoto A, Toda H, Shimato S, et al. Girdin maintains the stemness of glioblastoma stem cells. Oncogene. 2012; 31 (22): 2715-24. Epub 2011/10/25. DOI: 10.1038/onc.2011.466. PubMed PMID: 22020337.

39. Желтухин А. О., Соболева А. В., Сосновцева А. О., Ле Т. Х., Ильинская Г. В., Кочетков Д. В., и др. Энтеровирусы человека проявляют избирательную онколитическую активность на модели ксенотрансплантатов мультиформной глиобластомы человека в иммунодесицитных мышах. Вестник РГМУ. 2018; 2: 45-52.

40. Чумаков П. М., Морозова В. В., Бабкин И. В., Байков И. К., Нетесов С. В., Тикунова Н. В. Онколитические энтеровирусы. Молекулярная биология. 2012; 46 (6): 712-25.

41. Voroshilova MK. Interferon-producing enterovirus vaccines. (Live enterovirus vaccines, their interfering and interferonogenic activity and their use for prophylaxis of enteroviral and respiratory infections). Crit Rev Clin Lab Sci. 1970: 117-8.

42. Bøyum A, Scand. J. Isolation of mononuclear cells and gr anulocytes from human blood. (Paper IV). Clin Lab Invest. 1968; 97 (21 Suppl.): 77-89.

43. Zheltukhin AO, Sidorenko AS, Kriukova KK, Golbin DA, Tereshkova AV. Persistent virus presence during experimental oncolytic virus therapy in the model of subcutaneous mouse xenografts of human gliobolastoma multiforme. J Pharm Sci Res. 2017; 9 (11): 2224-6.

44. Yamayoshi S, lizuka S, Yamashita T, Minagawa H, Mizuta K, Okamoto $\mathrm{M}$, et al. Human SCARB2-dependent infection by coxsackievirus A7, A14, and A16 and enterovirus 71. J Virol. 2012; 86 (10): 5686-96. Epub 2012/03/23. DOI: 10.1128/ jvi.00020-12. PubMed PMID: 22438546; PubMed Central PMCID: PMCPMC3347270.

\section{References}

1. Sosnovtceva AO, Grinenko NF, Lipatova AV, Chumakov PM, Chekhonin VP. Onkoliticheskie virusy v terapii zlorfchestvennyh gliom. Biomeditsinskaia khimiia. 2016; 62 (4): 376-90. Epub 2016/08/27. DOI: 10.18097/pbmc20166204376. PubMed
PMID: 27562991.

2. Gubanova NV, Gaytan AS, Razumov IA, Mordvinov VA, Krivoshapkin AL, Netesov SV, i dr. Onkoliticheskie virusy v terapii gliom. Molecularnaja Biologija. 2012; 46 (6): 726-38. 
3. Wakimoto H, Kesari S, Farrell CJ, Curry WT, Jr, Zaupa C, Aghi M, et al. Human glioblastoma-derived cancer stem cells: establishment of invasive glioma models and treatment with oncolytic herpes simplex virus vectors. Cancer Res. 2009; 69 (8): 3472-81.

4. Alonso MM, Jiang H, Gomez-Manzano C, Fueyo J. Targeting brain tumor stem cells with oncolytic adenoviruses. Methods Mol Biol. 2012; 797: 111-25.

5. Cheema TA, Wakimoto H, Fecci PE, Ning J, Kuroda T, Jeyaretna DS, et al. Multifaceted oncolytic virus therapy for glioblastoma in an immunocompetent cancer stem cell model. Proc Natl Acad Sci USA. 2013; 110 (29): 12006-11. Epub 2013/06/12. DOI: 10.1073/pnas.1307935110. PubMed PMID: 23754388; PubMed Central PMCID: PMCPMC3718117.

6. van den Hengel SK, Balvers RK, Dautzenberg IJ, van den Wollenberg DJ, Kloezeman JJ, Lamfers ML, et al. Heterogeneous reovirus susceptibility in human glioblastoma stem-like cell cultures. Cancer Gene Ther. 2013; 20 (9): 507-13. Epub 2013/08/03. DOI: 10.1038/cgt.2013.47. PubMed PMID: 23907517.

7. Zhu Z, Gorman MJ, McKenzie LD, Chai JN, Hubert CG, Prager BC et al. Zika virus has oncolytic activity against glioblastoma stem cells. J Exp Med. 2017; 214 (10): 2843-57. Epub 2017/09/07. DOI: 10.1084/jem.20171093. PubMed PMID: 28874392; PubMed Central PMCID: PMCPMC5626408.

8. Csatary LK, Bakacs T. Use of Newcastle disease virus vaccine $(\mathrm{MTH}-68 / \mathrm{H})$ in a patient with high-grade glioblastoma. JAMA 1999; 281 (17): 588-9.

9. Hanahan D, Weinberg RA. Hallmarks of cancer: the next generation. Cell. 2011; 144 (5): 646-74.

10. Zheltukhin AO, Chumakov PM. Povstdnevnye i induziuemye funkzii gena p53. Uspehi biologicheskoj chimii. 2010; 50: 447516.

11. Chumakov PM. Function of the p53 gene: choice between life and death. Biochemistry Biokhimira. 2000; 65 (1): 28-40.

12. Chumakov PM. Versatile functions of $\mathrm{p} 53$ protein in multicellular organisms. Biochemistry (Mosc). 2007; 72 (13): 1399-421. Epub 2008/02/20. DOI: BCM72131399 [pii]. PubMed PMID: 18282133; PubMed Central PMCID: PMC2709848.

13. Ivashkiv LB, Donlin LT. Regulation of type I interferon responses. Nat Rev Immunol. 2014; 14 (1): 36-49. Epub 2013/12/24. DOI: 10.1038/nri3581. PubMed PMID: 24362405; PubMed Central PMCID: PMCPMC4084561.

14. Stark GR, Darnell JE, Jr. The JAK-STAT pathway at twenty Immunity. 2012; 36 (4): 503-14. Epub 2012/04/24. DOI: 10.1016/j.immuni.2012.03.013. PubMed PMID: 22520844; PubMed Central PMCID: PMCPMC3909993.

15. Zitvogel L, Galluzzi L, Kepp O, Smyth MJ, Kroemer G. Type I interferons in anticancer immunity. Nat Rev Immunol. 2015; 15 (7): 405-14. Epub 2015/06/02. DOI: 10.1038/nri3845. PubMed PMID: 26027717.

16. Groner B, von Manstein V. Jak Stat signaling and cancer: Opportunities, benefits and side effects of targeted inhibition. Mol Cell Endocrinol. 2017; 451: 1-14. Epub 2017/06/04. DOl: 10.1016/j.mce.2017.05.033. PubMed PMID: 28576744.

17. Heiber JF, Barber GN. Evaluation of innate immune signaling pathways in transformed cells. Methods Mol Biol. 2012; 797: 217-38.

18. Li Q, Tainsky MA. Epigenetic silencing of IRF7 and/or IRF5 in lung cancer cells leads to increased sensitivity to oncolytic viruses. PLoS One. 2011; 6 (12): e28683. Epub 2011/12/24 DOI: 10.1371/journal.pone.0028683. PubMed PMID: 22194884; PubMed Central PMCID: PMCPMC3237484.

19. Pikor LA, Bell JC, Diallo J-S. Oncolytic viruses: exploiting cancer's deal with the Devil. Trends in Cancer. 2015; 1 (4): 266-77.

20. Stojdl DF, Lichty B, Knowles S, Marius R, Atkins H, Sonenberg N, et al. Exploiting tumor-specific defects in the interferon pathway with a previously unknown oncolytic virus. Nat Med. 2000; 6 (7) $821-5$

21. Bell JC, McFadden G. Editorial overview: Oncolytic virusesreplicating virus therapeutics for the treatment of cancer. Cur Opin Virol. 2015; 13: viii-ix. Epub 2015/08/12. DOI: 10.1016/j. coviro.2015.07.005. PubMed PMID: 26260227.

22. Fukuhara $\mathrm{H}$, Ino $\mathrm{Y}$, Todo T. Oncolytic virus therapy: A new era of cancer treatment at dawn. Cancer Sci. 2016; 107 (10): 1373-9.
Epub 2016/10/30. DOI: 10.1111/cas.13027. PubMed PMID: 27486853; PubMed Central PMCID: PMCPMC5084676.

23. Naik S, Russell SJ. Engineering oncolytic viruses to exploit tumor specific defects in innate immune signaling pathways. Expert Opin Biol Ther. 2009; 9 (9): 1163-76.

24. Russell SJ, Peng KW, Bell JC. Oncolytic virotherapy. Nat Biotechnol. 2012; 30 (7): 658-70.

25. Keller BA, Bell JC. Oncolytic viruses-immunotherapeutics on the rise. J Mol Med (Berl). 2016; 94 (9): 979-91. Epub 2016/08/06. DOI: 10.1007/s00109-016-1453-9. PubMed PMID: 27492706.

26. Miao D, Van Allen EM. Genomic determinants of cancer immunotherapy. Curr Opin Immunol. 2016; 41: 32-8. Epub 2016/06/03. DOI: 10.1016/j.coi.2016.05.010. PubMed PMID: 27254251

27. Papaioannou NE, Beniata OV, Vitsos P, Tsitsilonis O, Samara P. Harnessing the immune system to improve cancer therapy. Annals of translational medicine. 2016; 4 (14): 261. Epub 2016/08/27. DOI: 10.21037/atm.2016.04.01. PubMed PMID: 27563648; PubMed Central PMCID: PMCPMC4971375.

28. Shen W, Patnaik MM, Ruiz A, Russell SJ, Peng KW. Immunovirotherapy with vesicular stomatitis virus and PD-L1 blockade enhances therapeutic outcome in murine acute myeloid leukemia. Blood. 2016; 127 (11): 1449-58. Epub 2015/12/30. DOI: 10.1182/blood-2015-06-652503. PubMed PMID: 26712908; PubMed Central PMCID: PMCPMC4797021.

29. Liston A, Farr AG, Chen Z, Benoist C, Mathis D, Manley NR, et al. Lack of Foxp3 function and expression in the thymic epithelium. J Exp Med. 2007; 204 (3): 475-80. Epub 2007/03/14. DOl: 10.1084/jem.20062465. PubMed PMID: 17353370; PubMed Central PMCID: PMCPMC2137899.

30. Parney IF, Petruk KC, Zhang C, Farr-Jones M, Sykes DB, Chang LJ. Granulocyte-macrophage colony-stimulating factor and B7-2 combination immunogene therapy in an allogeneic Hu-PBL-SCID/ beige mouse-human glioblastoma multiforme model. Hum Gene Ther. 1997; 8 (9): 1073-85. Epub 1997/06/10. DOI: 10.1089/ hum.1997.8.9-1073. PubMed PMID: 9189765.

31. Willmon C, Harrington K, Kottke T, Prestwich R, Melcher A, Vile R. Cell carriers for oncolytic viruses: Fed Ex for cancer therapy. Mo Ther. 2009; 17 (10): 1667-76.

32. Collet G, Grillon C, Nadim M, Kieda C. Trojan horse at cellular level for tumor gene therapies. Gene. 2013; 525 (2): 208-16. Epub 2013/04/02. DOI: 10.1016/j.gene.2013.03.057. PubMed PMID: 23542073.

33. Pan PY, Chen HM, Chen SH. Myeloid-derived suppressor cells as a Trojan horse: A cellular vehicle for the delivery of oncolytic viruses. Oncoimmunology. 2013; 2 (8): e25083. Epub 2013/10/02. DOI: 10.4161/onci.25083. PubMed PMID: 24083075; PubMed Central PMCID: PMCPMC3782526.

34. Kim SS, Pirollo KF, Chang EH. Isolation and Culturing of Glioma Cancer Stem Cells. Current protocols in cell biology. 2015; 67: 23.10.1-10. Epub 2015/06/11. DOI: 10.1002/0471143030. cb2310s67. PubMed PMID: 26061242; PubMed Central PMCID: PMCPmc4471477.

35. Lathia JD, Mack SC, Mulkearns-Hubert EE, Valentim CL, Rich JN. Cancer stem cells in glioblastoma. Genes Dev. 2015; 29 (12): 1203-17. Epub 2015/06/26. DOI: 10.1101/gad.261982.115. PubMed PMID: 26109046; PubMed Central PMCID: PMCPMC4495393.

36. Shaheen S, Ahmed M, Lorenzi F, Nateri AS. Spheroid-Formation (Colonosphere) Assay for in Vitro Assessment and Expansion of Stem Cells in Colon Cancer. Stem Cell Rev. 2016; 12 (4): 492-9. Epub 2016/05/22. DOI: 10.1007/s12015-016-9664-6. PubMed PMID: 27207017

37. Dashzeveg NK, Taftaf R, Ramos EK, Torre-Healy L, Chumakova A, Silver DJ, et al. New Advances and Challenges of Targeting Cancer Stem Cells. Cancer Res. 2017; 77 (19): 5222-7. Epub 2017/09/21. DOl: 10.1158/0008-5472.can-17-0054. PubMed PMID: 28928129

38. Natsume A, Kato T, Kinjo S, Enomoto A, Toda H, Shimato $S$, et al. Girdin maintains the stemness of glioblastoma stem cells. Oncogene. 2012; 31 (22): 2715-24. Epub 2011/10/25. DOI: 10.1038/onc.2011.466. PubMed PMID: 22020337.

39. Zheltukhin AO, Soboleva AV, Sosnovtseva AO, Le TH, llyinskaya GV 
Kochetkov DV, et al. Human enteroviruses exhibit selective oncolytic activity in the model of human glioblastoma multiforme xenografts in immunodeficient mice. Vestn RSMU. 2018; 2: 42-49

40. Chumakov PM, Moosova W, Babkin IV, Baykov IK, Netesov CV, Tikunova NV. Onkoliticheskie enterovirusy. Molekuljarnaja biologija. 2012; 46 (6): 712-25.

41. Voroshilova MK. Interferon-producing enterovirus vaccines. (Live enterovirus vaccines, their interfering and interferonogenic activity and their use for prophylaxis of enteroviral and respiratory infections). Crit Rev Clin Lab Sci. 1970: 117-8.

42. Bøyum A, Scand. J. Isolation of mononuclear cells and gr anulocytes from human blood. (Paper IV). Clin Lab Invest. 1968; 97 (21 Suppl.): 77-89.
43. Zheltukhin AO, Sidorenko AS, Kriukova KK, Golbin DA, Tereshkova AV. Persistent virus presence during experimental oncolytic virus therapy in the model of subcutaneous mouse xenografts of human gliobolastoma multiforme. J Pharm Sci Res. 2017; 9 (11): 2224-6.

44. Yamayoshi S, lizuka S, Yamashita T, Minagawa H, Mizuta K, Okamoto $\mathrm{M}$, et al. Human SCARB2-dependent infection by coxsackievirus A7, A14, and A16 and enterovirus 71. J Virol. 2012; 86 (10): 5686-96. Epub 2012/03/23. DOl: 10.1128/ jvi.00020-12. PubMed PMID: 22438546; PubMed Central PMCID: PMCPMC3347270. 